\title{
Hypermethylation of hepatic Gck promoter in ageing rats contributes to diabetogenic potential
}

\author{
M. H. Jiang • J. Fei • M. S. Lan • Z. P. Lu • M. Liu • \\ W. W. Fan $\cdot$ X. Gao $\cdot$ D. R. Lu
}

Received: 26 February 2008 / Accepted: 7 April 2008 / Published online: 22 May 2008

(C) Springer-Verlag 2008

\begin{abstract}
Aims/hypothesis Hepatic glucokinase (GCK) is a key enzyme in glucose utilisation. Downregulation of its activity is associated with insulin resistance and type 2 diabetes mellitus. However, it is unknown whether hepatic Gck expression is influenced by age and is involved in ageing-mediated diabetes, and whether the degree of methylation of the hepatic Gck promoter is correlated with the transcription of Gck. To address the question, we evaluated hepatic Gck transcription and promoter methylation in young (14 weeks), adult (40 weeks) and aged ( 80 weeks) rats.

Methods Hepatic glycogen, Gck expression and the kinase activity of GCK were measured in three age groups. The $\mathrm{CpG}$ methylation status was determined by both bisulphite direct sequencing and clone sequencing of the PCR amplificates of Gck promoter. The causal relationship between Gck methylation and mRNA expression was
\end{abstract}

Electronic supplementary material The online version of this article (doi:10.1007/s00125-008-1034-8) contains supplementary material, which is available to authorised users.

M. H. Jiang · J. Fei · Z. P. Lu • W. W. Fan • D. R. Lu (凶)

State Key Laboratory of Genetic Engineering,

School of Life Science and Institute of Biomedical Sciences,

Fudan University, 220 Handan Road, Shanghai, China 200433

e-mail: drlu@fudan.edu.cn

M. S. Lan

Department of Pediatrics, LSUHSC,

The Research Institute for Children, Children's Hospital,

New Orleans, LA, USA

M. Liu $\cdot$ X. Gao

Department of Endocrinology, Zhongshan Hospital,

Fudan University,

Shanghai, China confirmed by treating rat primary hepatocytes with 5-aza2'-deoxycytidine (5-Aza-CdR).

Results We have shown an age-associated decline in hepatic glycogen, Gck expression levels and the kinase activity of hepatic GCK. The eleven $\mathrm{CpG}$ sites studied displayed age-related progressive methylation changes in hepatic Gck promoter, which were confirmed by two methods: direct and clone sequencing. After 5-Aza-CdR treatment of rat primary hepatocytes, there was a fourfold increase in Gck expression.

Conclusions/interpretation Our results demonstrate that an age-related increase in methylation is negatively associated with hepatic Gck expression, suggesting that DNA methylation could be involved in increasing age-dependent susceptibility to hepatic insulin resistance and diabetes. Thus, the epigenetic modification of the hepatic Gck promoter may represent an important marker for diabetogenic potential during the ageing process.

Keywords Ageing · Diabetes · Glucokinase · Insulin resistance $\cdot$ Methylation

$\begin{array}{ll}\text { Abbreviations } \\ \text { 5-Aza-CdR } & \text { 5-aza-2'-deoxycytidine } \\ \text { GCK } & \text { glucokinase } \\ \text { nt } & \text { nucleotide }\end{array}$

\section{Introduction}

Insulin resistance, glucose intolerance and type 2 diabetes mellitus are becoming progressively more common in older populations [1-3]. These age-related changes may be caused in part by increased adiposity and the decreased 
Table 1 Primer sequences for real-time PCR and bisulphite sequencing PCR of hepatic Gck promoter

\begin{tabular}{lll}
\hline Parameter & Forward primer $\left(5^{\prime} \rightarrow 3^{\prime}\right)$ & Reverse $\operatorname{primer}\left(5^{\prime} \rightarrow 3^{\prime}\right)$ \\
\hline mRNA expression by real-time PCR & \\
Gck & AGTATGACCGGATGGTGGAT & CCGTGGAACAGAAGGTTCTC \\
Hprt & CTCATGGACTGATTATGGACAGGAC & GCAGGTCAGCAAAGAACTTATAGCC \\
Beta-actin & GATTACTGCCCTGGCTCCTA & TCATCGTACTCCTGCTTGCT \\
Bisulphite sequencing PCR of Gck promoter & \\
pMGck 1 st & GAATTTTATAGAAGAGTTTAGAATGTTTTGG & CACACCTTATAATATCCATAACCATCTC \\
pMGck 2nd & GGGTGTTAGGGTAGTTAGAGGATTTG & CCTAACTCCTAAAACCACCTATTAC \\
\hline
\end{tabular}

physical activity in older people [4, 5]. Although ageing plays a key role in the pathogenesis of insulin resistance, the underlying molecular mechanism is still poorly understood.

The pathophysiology of ageing and ageing-related diabetes is complex. Insulin resistance is a major contributor to development of the disease and to its complications [6-8]. Insulin resistance occurs because of defective insulinmediated glucose utilisation by the liver and peripheral tissues. The progression of insulin resistance to diabetes is caused by numerous metabolic events spanning a period of many years [9-11]. Glucose phosphorylation by glucokinase (GCK) is the initial event in glucose metabolism in the liver. Thus, glucose phosphorylation by GCK is important in the regulation of glucose utilisation in hepatocytes. The main role of insulin in the activation of glycolytic genes appears to be the stimulation of GCK synthesis, which leads to increased glucose utilisation [12-16]. Regulation of Gck activity is mainly due to changes in the transcription of this gene. In fact, decreased GCK enzymatic activity has been reported in patients with type 2 diabetes mellitus [17], and mutations in the Gck gene can cause MODY-2 [18, 19]. Accordingly, Gck is considered to be as a diabetessusceptibility gene.

Since type 2 diabetes mellitus incidence increases in older populations and their metabolic situations deteriorate over time, we hypothesised that the effect of age on glucose metabolism is associated with the level of hepatic Gck transcription and attempted to investigate mechanisms of the age regulation of $G c k$ expression in liver. Ling et al demonstrated that DNA methylation is associated with agedependent decline in NDUFB6 expression in human skeletal muscle [20], opening up the possibility that involvement of epigenetic factors like DNA methylation could predispose an individual to insulin resistance and type 2 diabetes mellitus. Accordingly, we specifically examined whether epigenetic modification was involved in the regulation of hepatic Gck expression in rats during postnatal life and whether it played a role in the pathogenesis of insulin resistance.

The aim of this study was to test whether the level of Gck expression and the activity of hepatic GCK were agerelated and whether the degree of DNA methylation in Gck promoter changes with age, from young (14 weeks) to adult (40 weeks) and aged ( 80 weeks) animals. In addition, to reveal the functional significance of DNA methylation in rat livers, we also investigated whether $G c k$ expression can be reactivated after treating rat primary hepatocytes with the DNA methyltransferase inhibitor, 5-aza-2'-deoxycytidine (5-Aza-CdR).

\section{Methods}

Animals Male Wistar rats were obtained from the Animal Developmental Center, Chinese Academy of Sciences, Shanghai. We used three different age groups $(n=7$ rats per group): 14 weeks (young), 40 weeks (adult) and 80 weeks (aged) in this study. Rats were housed under standard lightdark conditions (12/12 h light/dark cycle) and were given free access to commercial laboratory animal chow diet. Experiments were carried out after $16 \mathrm{~h}$ fasting. All experimental procedures involving the use of animals were conducted in accordance with NIH Guidelines and were reviewed and approved by the Animal Use and Care Committee of Fudan University.

Glycogen determination The content of hepatic glycogen was measured as described [21, 22]. Briefly, livers were weighed and incubated in four volumes (vol./wt) $1 \mathrm{~mol} /$ $1 \mathrm{KOH}$ for $20 \mathrm{~min}$ at $100^{\circ} \mathrm{C}$. After cooling, the lysates were diluted tenfold with water then added slowly to the anthrone reagent, which was placed in cold water to prevent excessive heating. After mixing by lateral shaking, the tube was placed in a boiling water bath for exactly 5 min for colour development and subsequently cooled in tap water. Absorbance at $620 \mathrm{~nm}$ was measured against a blank control using glucose as a standard. The glycogen content was calculated using the formula: $\mathrm{mg}$ of glycogen per $\mathrm{g}$ of tissue $=\mathrm{Du} / \mathrm{Ds} \times 0.1 \times 40$ (fold total dilution $) \times 0.9$, where $\mathrm{D}_{\mathrm{U}}$ is the OD value of the unknown, $D_{\mathrm{S}}$ is the OD value of $0.1 \mathrm{mg}$ of glucose in standard solution and 0.9 is the factor for converting the glucose value into glycogen value. Triplicate samples per liver were analysed and data are presented as $\mathrm{mg}$ of glucose units per $\mathrm{g}$ of liver. 
RNA extraction and real-time PCR Total RNA was isolated from liver tissues using Trizol reagent (Invitrogen, Carlsbad, CA, USA). cDNA was synthesised by reverse transcription using ReverTra Ace (Toyobo, Osaka, Japan). The primer sequences of rat Gck, housekeeping gene hypoxanthine phosphoribosyl-transferase (Hprt) [23] and beta-actin for quantitative RT-PCR are shown in Table 1. A $10 \mu \mathrm{l}$ reaction mixture contained $1 \mu \mathrm{l}$ of $\mathrm{cDNA}$ and $125 \mathrm{nmol} / \mathrm{l}$ of primers. The SYBR Green PCR Master Mix (Toyobo, Osaka, Japan) was used for PCR. The amplification and detection of specific products were performed using a sequence detection system (ABI PRISM7900; Applied Biosystems, Foster City, CA, USA). PCR cycle conditions were $95^{\circ} \mathrm{C}$ for $2 \mathrm{~min}$, followed by 40 cycles of denaturation at $95^{\circ} \mathrm{C}$ for $15 \mathrm{~s}$ and annealing and extension at $60^{\circ} \mathrm{C}$ for $1 \mathrm{~min}$. Reactions were performed in triplicate with rat Hprt and beta-actin as an internal control. Fluorescent signals were normalised to an internal reference $(\Delta R \mathrm{n})$ and the threshold cycle $(C \mathrm{t})$ was set within the exponential phase of PCR. The relative gene expression was calculated by comparing cycles for each target PCR. Cycle threshold values were converted to relative gene expression levels using the $2^{-\Delta \Delta C T}$ method [24].

Determination of GCK activities GCK activity was determined as described [25, 26]. Liver tissue (50 mg) was homogenised and diluted 20 times by buffer containing $50 \mathrm{mmol} / \mathrm{l} \mathrm{HEPES}, 5 \mathrm{mmol} / \mathrm{l} \mathrm{MgCl} 2,1 \mathrm{mmol} / \mathrm{l}$ EDTA, $100 \mathrm{mmol} / 1 \mathrm{KCl}$ and $2.5 \mathrm{mmol} / 1$ dithioerythritol at $\mathrm{pH} 7.4$. The homogenate was then passed through a 23-gauge needle syringe (five times) to ensure the proper tissue suspension and later centrifuged at $10,000 \times g$ and $4^{\circ} \mathrm{C}$. The reaction was started with $0.5 \mathrm{mmol} / \mathrm{LAD}+, 4 \mathrm{U}$ glucose-6phosphate dehydrogenase and $5 \mathrm{mmol} / 1 \mathrm{ATP}$ at $30^{\circ} \mathrm{C}$. The continuous spectrophotometric assay of glucose-phosphorylating activity was performed at two glucose concentrations: $100 \mathrm{mmol} / 1$ (measures all hexokinases, including GCK) and $0.5 \mathrm{mmol} / 1$ (measures only the low- $K_{\mathrm{m}}$ hexokinases). The difference between the two assays gives GCK activity. One unit is the amount of enzyme that catalyses the formation of $1 \mu \mathrm{mol}$ of substrate per min under the conditions of assay. The Bio-Rad DC (Bio-Rad Laboratories, Hercules, CA, USA) protein assay method was used to measure protein concentration.

Bisulphite-sequencing of Gck promoter All reagents were purchased from Sigma (St Louis, MO, USA). Genomic DNA was prepared from the livers of three groups using the SDS and proteinase $\mathrm{K}$ methods, and then subjected to sodium bisulphite treatment [27]. The Gck hepatic promoter sequence ( -518 to 83 ) was amplified with AmpliTaq Gold polymerase (Applied Biosystems, Warrington, UK) by two rounds of PCR. Bisulphite-sequencing primers for rat $G c k$ promoter were synthesised according to the reported sequences [28] (Table 1). PCR of the rat Gck promoter was performed under the following conditions: (1st round) $1 \min 95^{\circ} \mathrm{C}, 2 \min 50^{\circ} \mathrm{C}, 2 \min 72^{\circ} \mathrm{C}$ for five cycles, then $1 \min 95^{\circ} \mathrm{C}, 1 \min 50^{\circ} \mathrm{C}, 1 \min 72^{\circ} \mathrm{C}$ for 30 cycles. The first round products $(2 \mu \mathrm{l})$ were then subjected to a second round PCR under the following conditions: (second round) $1 \min 95^{\circ} \mathrm{C}, 2 \min 58^{\circ} \mathrm{C}, 1 \min 30 \mathrm{~s} 72^{\circ} \mathrm{C}$ for 35 cycles. We then sequenced $1 \mu$ of the second round PCR product using a DNA sequencer (ABI PRISM 3730; Applied Biosystems, Foster City, CA, USA) with dye terminators (Perkin-Elmer, Foster City, CA, USA). The rest of the PCR products were kept and used in the following experiments.

Quantification of methylation levels We used two methods to analyse levels of DNA methylation. First, we directly calculated the methylation level by measuring the heights of cytosine (shown as ' $\mathrm{C}$ ') and thymine (shown as ' $\mathrm{T}$ ') peaks at each CpG [29-33]. A single ' $\mathrm{C}$ ' at the corresponding $\mathrm{CpG}$ site was considered to be $100 \%$ methylation and a single ' $\mathrm{T}$ ' was considered to be no methylation; overlap of ' $\mathrm{C}$ ' and ' $\mathrm{T}$ ' was ranked as partial methylation. The percentage methylation was calculated as peak height of ' $C$ ' versus peak height of ' $\mathrm{C}$ ' plus peak height of ' $\mathrm{T}$ ' for each position.

In order to confirm whether the method above was reliable for estimation of methylation levels, we sequenced subclones of PCR products [34-36]. In brief, the residual PCR amplified products after direct sequencing were purified by gel electrophoresis and subcloned into a pGEM-T vector (Promega, Madison, WI, USA). A total of 30 clones per rat liver were isolated using a kit (QiaPrep Spin Plasmid Miniprep; Qiagen, Hilden, Germany) and sequenced. The methylation level for each $\mathrm{CpG}$ site was calculated by dividing the number of methylated $\mathrm{CpGs}$ of each site by the total number of clones sequenced.

Treatment of 5-Aza-CdR in rat primary hepatocytes Hepatocytes were isolated from a 40 -week adult male Wistar rat fasted for $48 \mathrm{~h}$ by two-stage collagenase perfusion of the liver as described [37]. The isolated hepatocytes were seeded at a density of $2 \times 10^{6}$ cells per $35 \mathrm{~mm}$ plate. After $6 \mathrm{~h}$ incubation at $37^{\circ} \mathrm{C}$ and $5 \% \mathrm{CO}_{2}$, attached cells were treated with freshly prepared $5 \mu \mathrm{mol} / 1$ 5-Aza-CdR (Sigma) and the medium was changed every $24 \mathrm{~h}$. RNA was isolated from both untreated and treated confluent hepatocytes after $72 \mathrm{~h}$ as described above. Then the transcription level of Gck was analysed with real-time PCR.

Statistical analyses Results are presented as mean \pm SD. Statistical analysis was conducted using the software package Minitab (version 15.1.0.0; Minitab, State College, PA, USA). Significance was assessed by Student's $t$ test and one-way ANOVA followed by Bonferroni $t$ test for the 
Table 2 General and biochemical characteristics

\begin{tabular}{llll}
\hline Characteristics & Young, 14 weeks & Adult, 40 weeks & Aged, 80 weeks \\
\hline$n$ & 7 & 7 & 7 \\
Weight $(\mathrm{g})$ & $248.7 \pm 25.0$ & $402.0 \pm 34.8^{* *}$ & $629.9 \pm 41.8^{* *}$ \\
Glucose (mmol/1) & $5.04 \pm 0.36$ & $5.02 \pm 0.22$ & $5.09 \pm 0.44$ \\
Insulin (pmol/1) & $174.5 \pm 17.9$ & $215.2 \pm 15.7^{* *}$ & $233.3 \pm 14.1^{* *} \boldsymbol{C}^{\dagger}$ \\
\hline
\end{tabular}

Values are means \pm SD

Results were analysed by Bonferroni $t$ test

${ }^{* *} p<0.01$ vs young rats; ${ }^{\dagger} p<0.05$ vs adult rats

comparisons of multiple means within an experiment, or by Kruskal-Wallis test and subsequent pair-wise comparisons. The statistical method used for each group of data is indicated and a $p$ value of less than 0.05 was considered to be statistically significant.

\section{Results}

Physical and biochemical characteristics of the experimental rats Body weights, basal plasma glucose, plasma insulin levels and liver glycogen contents from three different age groups (young, adult, aged) are listed in Table 2. The plasma glucose levels were comparable among the three groups, while the plasma insulin levels were elevated progressively in adult and aged rats compared with young rats $(p<0.01)$. We also observed a steady increase of body weight from young through to adult and aged rats.

Hepatic glycogen contents in three groups of rats Liver glycogen contents decreased with age, the greatest difference (from $6.36 \pm 1.43 \mathrm{mg} / \mathrm{g}$ tissue to $4.76 \pm 1.11 \mathrm{mg} / \mathrm{g}$ tissue) occurring between the young and adult groups ( $p<$ $0.05)$. Only a moderate decrease of glycogen content was seen between adult and aged rats $(p>0.05)$ (Fig. 1a).
Gck expression and activity in different age groups To determine the age-related changes in the Gck gene products, we measured hepatic Gck mRNA levels and GCK enzymatic activities from three age groups. The Gck mRNA levels were comparable in real-time PCR with either rat Hprt or beta-actin as an internal control. As shown in Fig. 1b, hepatic Gck expression, with rat Hprt as an internal control, was $60 \%(p<0.05)$ lower in adult and $86 \%(p<$ 0.01 ) lower in aged groups than in the young animal group, respectively. Furthermore, the decrease trend of GCK activities in the three groups was very similar to that of Gck mRNA, i.e. about 50 and $80 \%$ decreases in adult and aged rats, respectively, compared with young rats (Fig. 1c). The results indicate that the age-related decline of hepatic GCK activity is mainly controlled at the transcription level and is consistent with the tendency of changes seen in hepatic glycogen contents.

Methylation levels of the Gck promoter in different age groups To determine whether the expression of Gck was correlated with the status of Gck promoter methylation, we analysed the methylation levels of Gck promoter. The Gck promoter structure [13, 28, 38], shown in Fig. 2a, encompassed $11 \mathrm{CpG}$ sites located at nucleotides (nt) $-349,-342$, $-330,-314,-280,-245,-236,-93,-85,-4$ and +5 . The promoter region of the rat hepatic Gck gene was amplified

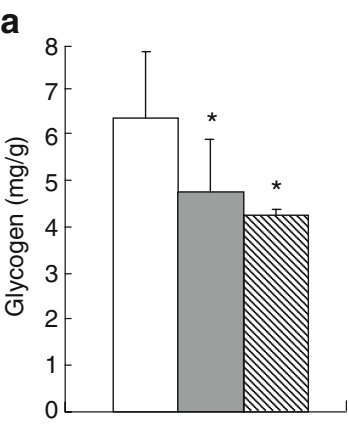

b

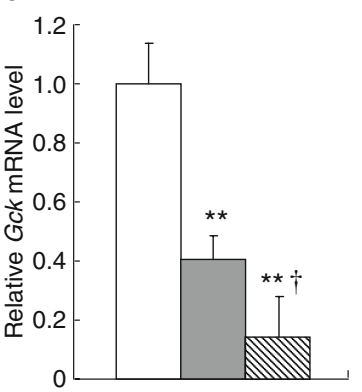

c

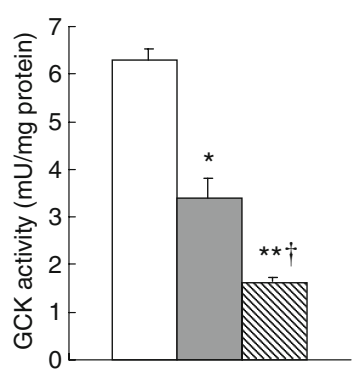

Fig. 1 Hepatic glycogen content (a), transcription of Gck using rat Hprt as a control (b) and hepatic GCK activities (c) in rat livers after $16 \mathrm{~h}$ fasting. White bars, young rats; grey bars, adult rats; hatched bars, aged rats. Values are means $\pm \mathrm{SD}, n=7$ rats per group. ${ }^{*} p<0.05$ and $* * p<0.01$ vs young rats; ${ }^{\dagger} p<0.05$ vs adult rats 


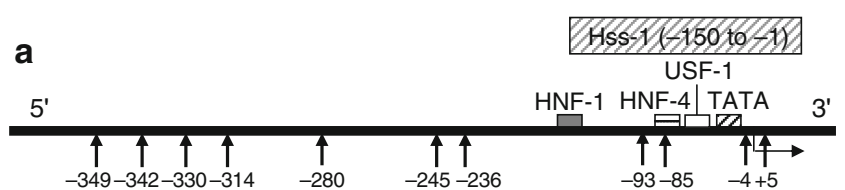

b
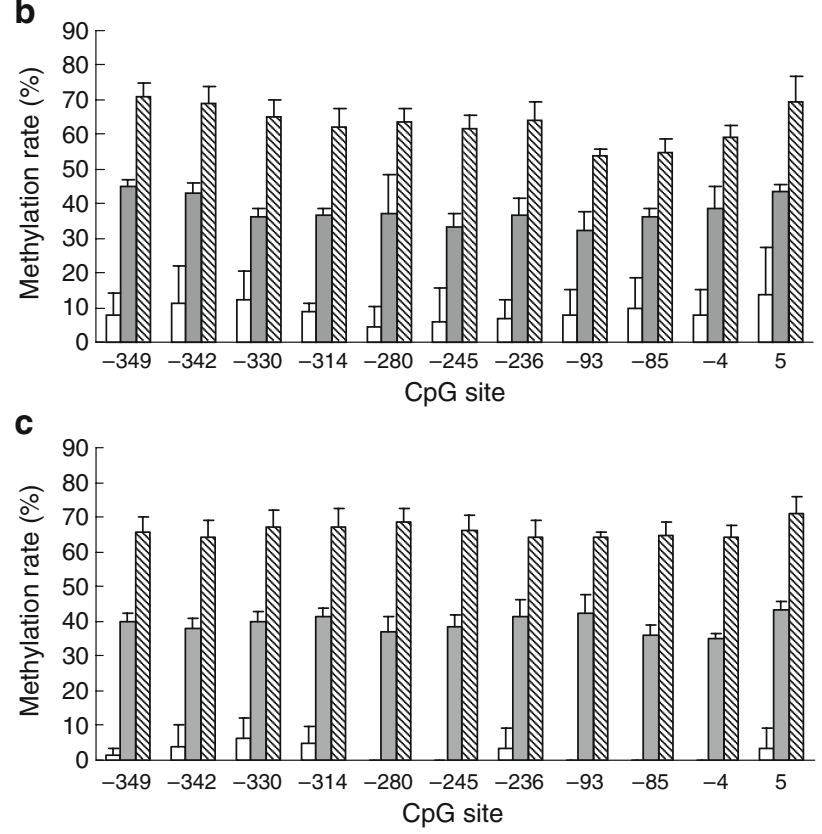

Fig. 2 Schematic diagram of Gck gene promoter structure and methylation status of hepatic Gck promoter in three age groups. a There are $11 \mathrm{CpG}$ sites within the promoter region (indicated by arrows) from nt -518 to $n t+83$. TATA box, DNase I hypersensitive sites (HSS-1) and binding sites of hepatic nuclear factor 1 (HNF-1), hepatic nuclear factor 4 (HNF-4) and upstream stimulatory factor 1 (USF-1) are also indicated. b Genomic DNA was modified by sodium bisulphite and amplified by two rounds of PCR. Then, PCR products were directly sequenced and the methylation percentage of the individual $\mathrm{CpG}$ site was calculated by peak height of the methylated residues (C) divided by the sum of methylated and unmethylated residues (C plus T). Methylation rate (\%) is represented as the average ratio of methylated cytosine to total cytosine (methylated plus unmethylated) of all samples in each group. c PCR products were subcloned into the pGEM-T vector. The levels of methylation were determined in 30 clones for each sample. White bars, young rats; grey bars, adult rats; hatched bars, aged rats. Values are means $\pm \mathrm{SD}, n=4-7$ rats per group. The difference of the overall methylation level between each groups is significant $(p<0.05)$

by nest PCR from nt -518 to $n t+83$ and sequenced directly. The sequencing results indicated that all non-CpG cytosines were converted to thymines, whereas the status and ratio of $\mathrm{C}$ : $(\mathrm{C}+\mathrm{T})$ was very different at each $\mathrm{CpG}$ site among the three groups. However, the ratios were almost identical in rats of the same age. In order to quantify the methylation levels, we calculated the methylation rates of individual $\mathrm{CpG}$ sites from the direct sequencing results. As shown in Fig. 2b, methylation levels of the $\mathrm{CpG}$ site in the Gck promoter were significantly different $(p<0.05)$ among the three age groups. The aged rats exhibited considerably higher methylation $(60-80 \%)$ of all $\mathrm{CpG}$ sites than that

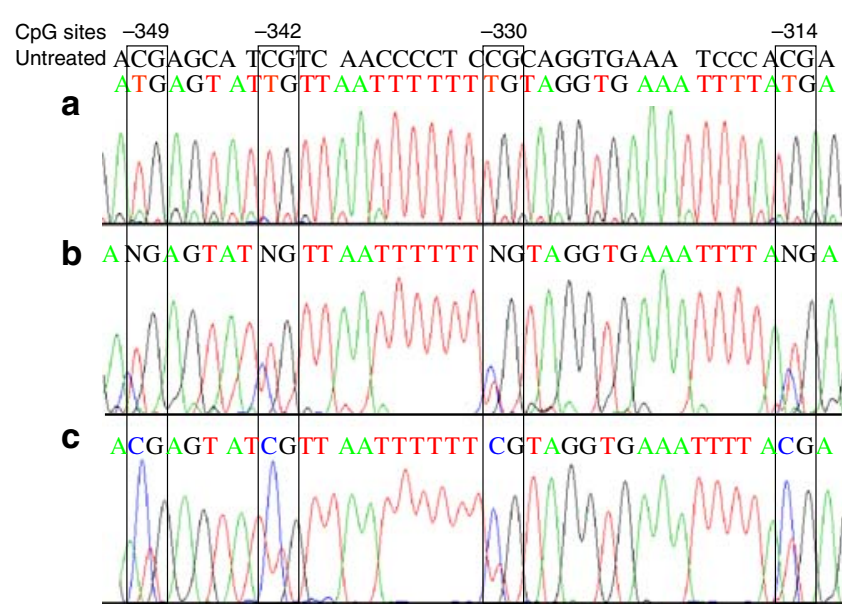

Fig. 3 Representational genomic sequencing chromatograms from nt -349 to $n t-314$ for each age group. DNA was first treated with sodium bisulphite, and the amplified PCR products were then directly subjected to sequencing. The upper sequence is the untreated Gck promoter sequence. Lower sequences are treated sequences in young rats (a), adult rats (b) and aged rats (c). The open boxes indicate the $\mathrm{CpG}$ sites

seen in the other two groups. The Gck promoter in adult rats showed a lower level of methylation (35-50\%), whereas the young rats showed the lowest methylation levels $(0-10 \%)$ in the $\mathrm{CpG}$ sites of the Gck promoter. Three representative DNA sequencing chromatograms are shown in Fig. 3. Different methylation levels of hepatic Gck promoter derived from the three age groups were shown to contain four $\mathrm{CpG}$ sites from nt -349 to $\mathrm{nt}-314$. We sequenced 30 clones of each individual PCR reaction to confirm the level of methylation. The patterns of $\mathrm{CpG}$ methylation analysed by these clones were similar to the direct bisulphite-sequencing method above. Only less than $10 \%$ differences between the two methods were seen at some of the $\mathrm{CpG}$ sites (Fig. 2c).

5-Aza-2'-deoxycytidine treatment of the primary rat hepatocytes upregulated Gck expression In order to establish whether Gck expression was influenced by methylation status, we treated primary adult rat hepatocytes with 5-Aza-

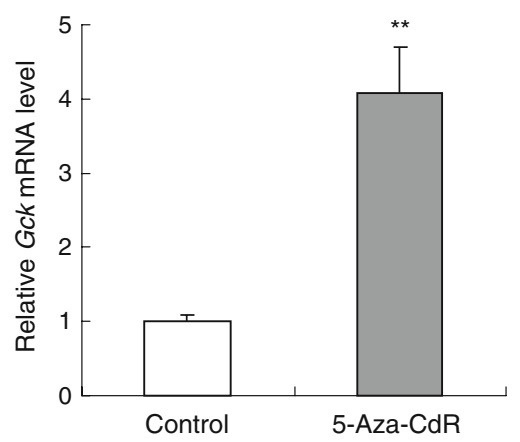

Fig. 4 Effects of 5-Aza-CdR on Gck (relative to Hprt) expression in primary rat hepatocytes. Values are means \pm SD of triplicate experiments. ${ }^{* *} p<0.01$ vs untreated cells (control) 


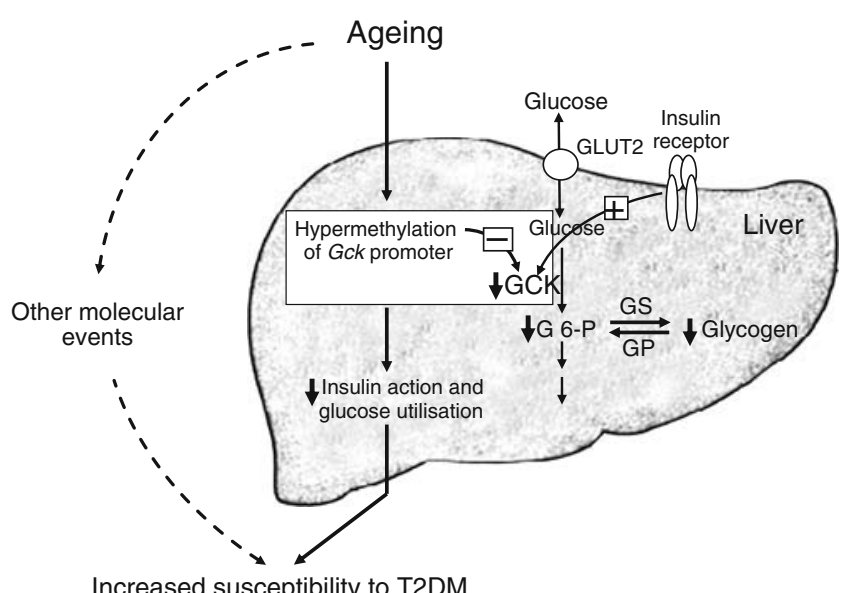

Increased susceptibility to T2DM

Fig. 5 Ageing-dependent hypermethylation of hepatic Gck promoter increases susceptibility to type 2 diabetes mellitus (T2DM) by downregulating Gck expression in rat liver. In hepatic glycolysis, glucose is transported through the hepatocyte plasma membrane by GLUT2. Hepatic GCK, induced by insulin, phosphorylates glucose to glucose 6-phosphate (G 6-P), which is an allosteric activator of glycogen synthase (GS). Promoter hypermethylation represses the expression of hepatic Gck, resulting in two effects in liver: (1) decreased insulin action and glucose utilisation; and (2) diminished glycogen synthesis. Other complex molecular events are also involved in age-related type 2 diabetes mellitus. Even though compensatory normoglycaemia is maintained, aged rats are highly susceptible to the disease. +, increased Gck expression; -, decreased Gck expression; downward arrows, significant decrease; solid line, efferent pathway; broken line, unknown pathway

CdR, a demethylating agent, for 3 days and then Gck mRNA expression was monitored. In Fig. 4, Gck mRNA was upregulated fourfold compared with the untreated hepatocytes. The result suggests that Gck expression was significantly reactivated by demethylation.

\section{Discussion}

Glucose intolerance may emerge during the human ageing process and is most often associated with normal or elevated plasma insulin concentrations [39]. Ageing promotes a state of insulin resistance primarily by blunting the action of insulin on the uptake of glucose in liver and peripheral tissues $[1,3]$. Levels of GCK, a rate-limiting enzyme in glycolysis, are reduced in liver of patients with type 2 diabetes mellitus and in diabetic animals [17, 40]. Nevertheless, it remains unknown whether ageing is associated with diabetes through a gradual downregulation of hepatic Gck expression. Furthermore, less is known about DNA methylation changes of the specific genes in ageing. The important finding of the present study is that age-related DNA methylation changes were associated with a decline in the expression of hepatic Gck during the ageing process of rats, which could add to the risk of insulin resistance and type 2 diabetes mellitus (Fig. 5). The epigenetic modification of hepatic Gck gene might be an important marker for diabetogenic potential during the ageing process. Recently, Ling C et al. [20] demonstrated that DNA methylation played a role in the pathogenesis of insulin resistance and type 2 diabetes mellitus. Our finding provides another example of how epigenetic factors are involved in an age-dependent increase of susceptibility to insulin resistance.

Insulin resistance in liver is a major contributor to the increased prevalence of type 2 diabetes mellitus with age. Hepatic glucose metabolism is a good predictor of insulin sensitivity. The primary function of insulin in liver is to stimulate the key enzyme of glycolysis, GCK, which enhances hepatic glucose disposal. To determine why insulin sensitivity decreases with age, we analysed the Gck expression and the activity of GCK in livers from young (14 weeks), adult (40 weeks) and aged ( 80 weeks) rats. The adult and the aged rats showed a sharp decrease in the transcription of Gck compared with the young group. These declines were of the same magnitude as that observed in GCK activities of adult and aged rats. We deduce from this that the downregulation of hepatic Gck with ageing would severely attenuate the effect of insulin in liver and diminish glucose utilisation (Fig. 5).

In our study, Gck expression levels in liver were positively associated with hepatic glycogen. Consistent with the trend of Gck expression, glycogen levels progressively decline with age. GCK plays a crucial role in glycogen synthesis, and small changes in its total activity resulted in much larger changes in glycogen synthesis [41, 42]. The potential mechanism of GCK-mediated glycogen synthesis might be through catalysation of glucose 6phosphate synthesis and promotion of glycogen synthase activation in hepatocytes [43-46] (Fig. 5). Furthermore, we determined the glycogen content in rat muscles, a tissue that does not express $G c k$, and found no difference among the three age groups (Electronic supplementary material [ESM] Fig. 1).

Considering the significant role of Gck expression in hepatic insulin resistance and glycogen synthesis, we explored the potential mechanisms of Gck expression with ageing. Here, we have presented data to support the notion that differential DNA methylation results in the agedependent reduction of Gck expression. The Gck promoter structure $[13,28,38]$ is shown in Fig. 2a. The same region of this gene was hypomethylated in the young livers, with less than $10 \%$ methylation, while in adult livers the percentage methylation increased significantly (about $50 \%$ ) and was highest (above 70\%) in aged liver in the region investigated (Fig. 2b, c). These results demonstrate that hepatic Gck promoter methylation increased gradually with ageing (Fig. 5). 
We quantified the methylation levels of Gck promoter in different age groups using bisulphite direct sequencing and clone sequencing of the PCR products derived from Gck promoter. In the present study, ' $\mathrm{T}$ ' and ' $\mathrm{C}$ ' overlapped at almost all of the $\mathrm{CpG}$ sites in the Gck promoter region, but there were significant differences in the three age groups (Fig. 3). From the sequencing chromatograms we directly calculated the degree of methylation of $11 \mathrm{CpG}$ sites in the promoter region (Fig. 2b). Furthermore, we also sequenced the subclones of bisulphite-treated Gck promoter to confirm the methylation levels (Fig. 2c). The methylation levels calculated by two methods were quite similar, with fewer than $10 \%$ differences at some of the $\mathrm{CpG}$ sites. The minor differences can probably be attributed to the background noise affecting the exact peak heights of ' $\mathrm{C}$ ' or ' $\mathrm{T}$ ' in the sequencing chromatogram, as well as to the number of clones selected in this study. In spite of the minor differences, these two methods generated consistent results for calculating DNA methylation levels. Especially the direct sequencing of the PCR product is relatively straightforward.

To confirm the links between methylation and gene expression, a demethylation agent, 5-Aza-CdR, was used to treat primary adult rat hepatocytes. 5-Aza-CdR is a cytosine analogue that acts as a suicide substrate for DNA methyltransferase and hence is an inhibitor of DNA methyltransferase when incorporated into DNA at $\mathrm{CpG}$ dinucleotides of the target site for DNA methylation [47]. As expected, 5-Aza-CdR significantly increased Gck mRNA transcription.

Gck gene has two promoters, one active in pancreas and the other active in liver [48]. We determined pancreatic Gck expression using real-time PCR. There were no significant differences in the three age groups, which was consistent with earlier studies [49]. Thus, we did not further study the methylation status of the Gck promoter specific to islets. We also quantified methylation of the liver-specific Gck promoter in rat skeletal muscles, a tissue that does not express Gck. Almost 100\% methylation was found at the same region of the Gck promoter in all age groups (ESM Fig. 2). We were not sure whether the hypermethylation of Gck promoter was the major factor in silencing Gck mRNA expression in muscle or other Gck non-expressing tissues. However, according to our findings, the degree of $\mathrm{CpG}$ methylation in the Gck promoter increased in an agedependent manner as a specific biological feature in rat livers, which should be the critical factor for suppression of Gck mRNA expression.

Ageing is associated with marked basal hyperinsulinaemia despite normal blood glucose. As shown in Table 2, the basal insulin levels were higher in the adult and aged rats than in young animals. Basal hyperinsulinaemia is suggestive of an insulin-resistant state, so both adult and aged rats exhibited marked whole-body insulin resistance. Furthermore, body weight increase (Table 2) and fat accumulation of healthy old rats might aggravate insulin resistance in liver and other insulin-targeting organs, so the combined impact of ageing and obesity on insulin sensitivity contributes greatly to insulin resistance in elderly people $[1,4,50]$. Accordingly, we cannot rule out the potential role of agerelated obesity in hypermethylation of the Gck promoter, since, under normal conditions, rats increase weight as they age. We have now begun a new study of Gck methylation in either ageing or obese rats. Our preliminary findings indicate that obesity could increase susceptibility to ageinduced insulin resistance and the level of hepatic Gck methylation in aged rats (M.H. Jiang, J. Fei, M.S. Lan, Z.P. Lu, M. Liu, W.W. Fan, X. Gao and D.R. Lu, unpublished results).

In summary, we have demonstrated that hypermethylation of hepatic Gck promoter is associated with the downregulation of hepatic Gck transcription in aged rats and contributes to diabetogenic potential (Fig. 5). However, the detailed mechanisms that link ageing and hypermethylation of Gck promoter still merit further investigation. Also, a systematic profiling of DNA methylation changes in the ageing process would yield valuable insights into the epigenetic mechanism of ageing, insulin resistance and other ageing-related diseases.

Acknowledgements We would like to thank J. Gu (Shanghai Experimental Animal Center, China Academy of Sciences, Shanghai, China) for his help with animal studies. This work was supported in part by the National Key Basic Research Program of China (2006CB503910), Science and Technology Commission of Shanghai Municipality (07JC14011) and Shanghai Leading Academic Discipline Project (B111).

Duality of interest The authors declare that there is no duality of interest associated with this manuscript.

\section{References}

1. Facchini FS, Hua N, Abbasi F, Reaven GM (2001) Insulin resistance as a predictor of age-related diseases. J Clin Endocrinol Metab 86:3574-3578

2. Reaven GM, Reaven EP (1985) Age, glucose intolerance, and non-insulin-dependent diabetes mellitus. J Am Geriatr Soc 33:286-290

3. Rowe JW, Minaker KL, Pallotta JA, Flier JS (1983) Characterization of the insulin resistance of aging. J Clin Invest 71:15811587

4. Fontana L, Klein S (2007) Aging, adiposity, and calorie restriction. JAMA 297:986-994

5. Stewart KJ (2005) Physical activity and aging. Ann N Y Acad Sci 1055:193-206

6. Burns N, Finucane FM, Hatunic M et al (2007) Early-onset type 2 diabetes in obese white subjects is characterised by a marked defect in beta cell insulin secretion, severe insulin resistance and a lack of response to aerobic exercise training. Diabetologia 50:1500-1508 
7. da Silva RC, Miranda WL, Chacra AR, Dib SA (2007) Insulin resistance, beta-cell function, and glucose tolerance in Brazilian adolescents with obesity or risk factors for type 2 diabetes mellitus. J Diabetes Complications 21:84-92

8. Meigs JB, Rutter MK, Sullivan LM, Fox CS, D'Agostino RB Sr, Wilson PW (2007) Impact of insulin resistance on risk of type 2 diabetes and cardiovascular disease in people with metabolic syndrome. Diabetes Care 30:1219-1225

9. Pereira S, Marliss EB, Morais JA, Chevalier S, Gougeon R (2008) Insulin resistance of protein metabolism in type 2 diabetes. Diabetes 57:56-63

10. Raz I, Eldor R, Cernea S, Shafrir E (2005) Diabetes: insulin resistance and derangements in lipid metabolism. Cure through intervention in fat transport and storage. Diabetes Metab Res Rev 21:3-14

11. Groop LC, Widen E, Ferrannini E (1993) Insulin resistance and insulin deficiency in the pathogenesis of type 2 (non-insulindependent) diabetes mellitus: errors of metabolism or of methods? Diabetologia 36:1326-1331

12. Walker DG, Rao S (1964) The role of glucokinase in the phosphorylation of glucose by rat liver. Biochem J 90:360-368

13. Magnuson MA, Andreone TL, Printz RL, Koch S, Granner DK (1989) Rat glucokinase gene: structure and regulation by insulin. Proc Natl Acad Sci U S A 86:4838-4842

14. Salas M, Vinuela E, Sols A (1963) Insulin-dependent synthesis of liver glucokinase in the rat. J Biol Chem 238:3535-3538

15. Iynedjian PB, Gjinovci A, Renold AE (1988) Stimulation by insulin of glucokinase gene transcription in liver of diabetic rats. $\mathrm{J}$ Biol Chem 263:740-744

16. Iynedjian PB, Pilot PR, Nouspikel T et al (1989) Differential expression and regulation of the glucokinase gene in liver and islets of Langerhans. Proc Natl Acad Sci U S A 86:7838-7842

17. Caro JF, Triester S, Patel VK, Tapscott EB, Frazier NL, Dohm GL (1995) Liver glucokinase: decreased activity in patients with type II diabetes. Horm Metab Res 27:19-22

18. Stoffel M, Patel P, Lo YM et al (1992) Missense glucokinase mutation in maturity-onset diabetes of the young and mutation screening in late-onset diabetes. Nat Genet 2:153-156

19. Vionnet N, Stoffel M, Takeda J et al (1992) Nonsense mutation in the glucokinase gene causes early-onset non-insulin-dependent diabetes mellitus. Nature 356:721-722

20. Ling C, Poulsen P, Simonsson S et al (2007) Genetic and epigenetic factors are associated with expression of respiratory chain component NDUFB6 in human skeletal muscle. J Clin Invest 117:3427-3435

21. Templeton M (1961) Microdetermination of glycogen with anthrone reagent. J Histochem Cytochem 9:670-672

22. Van Der Vies J (1954) Two methods for the determination of glycogen in liver. Biochem J 57:410-416

23. Chen J, Rider DA, Ruan R (2006) Identification of valid housekeeping genes and antioxidant enzyme gene expression change in the aging rat liver. J Gerontol A Biol Sci Med Sci 61:20-27

24. Ginzinger DG (2002) Gene quantification using real-time quantitative PCR: an emerging technology hits the mainstream. Exp Hematol 30:503-512

25. Bontemps F, Hue L, Hers HG (1978) Phosphorylation of glucose in isolated rat hepatocytes. Sigmoidal kinetics explained by the activity of glucokinase alone. Biochem J 174:603-611

26. Davidson AL, Arion WJ (1987) Factors underlying significant underestimations of glucokinase activity in crude liver extracts: physiological implications of higher cellular activity. Arch Biochem Biophys 253:156-167

27. Grunau C, Clark SJ, Rosenthal A (2001) Bisulfite genomic sequencing: systematic investigation of critical experimental parameters. Nucleic Acids Res 29:E65-E65
28. Bogdarina I, Murphy HC, Burns SP, Clark AJ (2004) Investigation of the role of epigenetic modification of the rat glucokinase gene in fetal programming. Life Sci 74:1407-1415

29. Li LC, Chui R, Nakajima K, Oh BR, Au HC, Dahiya R (2000) Frequent methylation of estrogen receptor in prostate cancer: correlation with tumor progression. Cancer Res 60:702-706

30. Millar DS, Ow KK, Paul CL, Russell PJ, Molloy PL, Clark SJ (1999) Detailed methylation analysis of the glutathione Stransferase pi (GSTP1) gene in prostate cancer. Oncogene 18:1313-1324

31. Paul CL, Clark SJ (1996) Cytosine methylation: quantitation by automated genomic sequencing and GENESCAN analysis. Biotechniques 21:126-133

32. Stirzaker C, Millar DS, Paul CL et al (1997) Extensive DNA methylation spanning the $\mathrm{Rb}$ promoter in retinoblastoma tumors. Cancer Res 57:2229-2237

33. Lewin J, Schmitt AO, Adorjan P, Hildmann T, Piepenbrock C (2004) Quantitative DNA methylation analysis based on four-dye trace data from direct sequencing of PCR amplificates. Bioinformatics 20:3005-3012

34. Ngo V, Gourdji D, Laverriere JN (1996) Site-specific methylation of the rat prolactin and growth hormone promoters correlates with gene expression. Mol Cell Biol 16:3245-3254

35. Tao Q, Robertson KD, Manns A, Hildesheim A, Ambinder RF (1998) Epstein-Barr virus (EBV) in endemic Burkitt's lymphoma: molecular analysis of primary tumor tissue. Blood 91:1373-1381

36. Murumagi A, Vahamurto P, Peterson P (2003) Characterization of regulatory elements and methylation pattern of the autoimmune regulator (AIRE) promoter. J Biol Chem 278:19784-19790

37. Salavert A, Iynedjian PB (1982) Regulation of phosphoenolpyruvate carboxykinase (GTP) synthesis in rat liver cells. Rapid induction of specific mRNA by glucagon or cyclic AMP and permissive effect of dexamethasone. J Biol Chem 257:1340413412

38. Bossard P, Parsa R, Decaux JF, Iynedjian P, Girard J (1993) Glucose administration induces the premature expression of liver glucokinase gene in newborn rats. Relation with DNase-Ihypersensitive sites. Eur J Biochem 215:883-892

39. Davidson MB (1979) The effect of aging on carbohydrate metabolism: a review of the English literature and a practical approach to the diagnosis of diabetes mellitus in the elderly. Metabolism 28:688-705

40. Ferre T, Pujol A, Riu E, Bosch F, Valera A (1996) Correction of diabetic alterations by glucokinase. Proc Natl Acad Sci U S A 93:7225-7230

41. Agius L, Peak M, Newgard CB, Gomez-Foix AM, Guinovart JJ (1996) Evidence for a role of glucose-induced translocation of glucokinase in the control of hepatic glycogen synthesis. J Biol Chem 271:30479-30486

42. Postic C, Shiota M, Niswender KD et al (1999) Dual roles for glucokinase in glucose homeostasis as determined by liver and pancreatic beta cell-specific gene knock-outs using Cre recombinase. J Biol Chem 274:305-315

43. Harndahl L, Schmoll D, Herling AW, Agius L (2006) The role of glucose 6-phosphate in mediating the effects of glucokinase overexpression on hepatic glucose metabolism. FEBS J 273:336-346

44. Hampson LJ, Agius L (2005) Increased potency and efficacy of combined phosphorylase inactivation and glucokinase activation in control of hepatocyte glycogen metabolism. Diabetes 54:617623

45. Gomis RR, Favre C, Garcia-Rocha M, Fernandez-Novell JM, Ferrer JC, Guinovart JJ (2003) Glucose 6-phosphate produced by gluconeogenesis and by glucokinase is equally effective in activating hepatic glycogen synthase. J Biol Chem 278:9740 9746 
46. Seoane J, Gomez-Foix AM, O'Doherty RM, Gomez-Ara C, Newgard CB, Guinovart JJ (1996) Glucose 6-phosphate produced by glucokinase, but not hexokinase I, promotes the activation of hepatic glycogen synthase. J Biol Chem 271:23756-23760

47. Antonsson BE, Avramis VI, Nyce J, Holcenberg JS (1987) Effect of 5-azacytidine and congeners on DNA methylation and expression of deoxycytidine kinase in the human lymphoid cell lines $\mathrm{CCRF} / \mathrm{CEM} / 0$ and $\mathrm{CCRF} / \mathrm{CEM} / \mathrm{dCk}-1$. Cancer Res 47:3672-3678
48. Magnuson MA, Shelton KD (1989) An alternate promoter in the glucokinase gene is active in the pancreatic beta cell. J Biol Chem 264:15936-15942

49. Frese T, Bazwinsky I, Muhlbauer E, Peschke E (2007) Circadian and age-dependent expression patterns of GLUT2 and glucokinase in the pancreatic beta-cell of diabetic and nondiabetic rats. Horm Metab Res 39:567-574

50. Adelman RC (1970) An age-dependent modification of enzyme regulation. J Biol Chem 245:1032-1035 